\title{
The influence of the Enterprise Resource Planning (ERP) on Management Controllers: A Study in the Tunisian Context
}

\author{
Chiraz Rouissi ${ }^{1}$ \\ ${ }^{1}$ Phd. Assistant Professor at the University of Jeddah, Saudi Arabia \\ Correspondence: Chiraz Rouissi, Phd. Assistant Professor at the University of Jeddah, Saudi Arabia. E-mail: \\ charrouissi@yahoo.fr
}

Received: January 5, 2020

Accepted: February 22, 2020

Online Published: March 7, 2020

doi:10.5539/ijbm.v15n4p25

URL: https://doi.org/10.5539/ijbm.v15n4p25

\begin{abstract}
The information system and in particular Enterprise Resource Planning are essential tools for management controllers. Nowadays, in large and medium-sized enterprises, information integration is carried out in most cases in an ERP environment. Management controllers have also seen the birth of their profession thanks to the changes made in organizations on information systems.

The main aim of this article is a question of identifying the expectations of the firm, of characterizing the ERP and of determining their potential impact on the management control systems.

This paper will present the influence of the key success factors (KSF) on the satisfaction of the management controller through quantitative research with a survey. To collect the data necessary for this research, a quantitative confirmatory study will be conducted.
\end{abstract}

Keywords: ERP, management control, information system, integration management software

\section{Introduction}

The information system and in particular Enterprise Resource Planning are essential tools for management controllers. Each company therefore tries to set up an information system that meets its specific needs.

In the field of management control, we can distinguish between what is "conceptual equipment" (formalized models and tools) and what comes under the "organizational device" (structures and behaviors).

In this article, we will focus on the implementation of an ERP and its impacts on the business of the management controller and more specifically, it will be necessary to present this new wave of information systems and to identify their impacts on the relationship of the management controller with managers. So, we will try:

- To present ERP as an information system component, and to show the importance of information systems in relation to management control.

- To better understand the contribution of ERP for the management controller.

To collect the data necessary for this research, a quantitative confirmatory study will be conducted.

The organization of this article as follow:

The first part will aim to study the concept of ERP as a component of information systems and to present the different contributions provided by this technology.

The second part will explain the evolution of the "management control" function and the impact of the introduction and use of ERP on the profession of management controller. An explanatory model of its impacts is presented with the resulting hypotheses and which is devoted to empirically testing the model developed.

\section{Theoretical Foundations of ERP and Management Control}

Indeed, the business environment has not stopped undergoing changes and mutations at all levels, whether economic, sociological or technological, in recent years, hence the paramount importance accorded by firms to information and communication technologies to be able to face increased competition and thus improve their competitive position.

To do this, companies need sophisticated, clear, precise information allowing immediate decision-making in 
order to gain on reaction times both on short- and long-term horizons, hence the perception of IT as the most effective means to achieve these ends and therefore of the information system as the basis for improving their organizational efficiency.

Hence the use of ERP which replaces traditional production management and planning systems and therefore responds to the problem of completeness and synchronization of information in the organization

\section{The Enterprise Resource Planning}

In this part, we will present the different definitions of ERP as well as their history, their basic principles and their perimeters.

\subsection{ERP Definition}

According to Reix (2004), he defines ERP as "A configurable, modular and integrated IT application, which aims to federate and optimize business management processes by proposing a unique repository and using standard management rules".

This definition underlines the standard character of this software package. In addition, it is important to note that the definition of ERP proposed by Perot in proves to be the most complete, this author affirms that ERP is defined as being: "Configurable and modular IT applications, which aim to federate and optimize the management processes of the company by proposing a single and coherent repository and by relying on standard management rules."

To summarize, these different definitions emphasize the concept of information system integration which works in a coordinated and coherent way.

So, we talk about ERP when we are in the presence of an information system composed of several applications sharing the same database, through a system automated predefined, possibly configurable (a workflow engine). In addition, the ERP are applied on the corporate to coordinate all the activities of the company (so-called vertical activities such as production, supply or horizontal such as marketing, sales forces, management of human resources, etc.) around the same information system.

\subsection{The History of an ERP}

At the end of the 1970s, the accounting and order entry functions were integrated into Computer Assisted Production Management (CAPM) systems to give birth to Manufacturing Resource Planning (MRP) which covers the keeping of the production master plan, management of tools, management of stocks, supplies, logistics...

During the 1980s, the needs of companies becoming more and more complex, we tried to make the link between accounting and electronic exchanges. A new generation of systems then appeared, the DRP (Distribution Resource Planning), which made it possible to coordinate the management of warehouses, distribution centers and the supply chain.

\subsection{The Scope of the ERP}

The vocation of an ERP is to standardize the IS of the company with a unique tool which is capable of covering a large management perimeter, including purchasing management, sales management, accounting management (customer accounting, supplier, fixed assets, personnel), management control, production management (planning, ...), inventory management (logistics).

The ERP is made up of functional modules, each covering a business management scope. For example, entering a sale automatically generates a double entry accounting entry in the sales journal with automatic calculation of the collected VAT. An example of ERP concerned by the management controller: SAPR /3. It seems interesting to us to present the characteristics of an ERP: SAP

Headquartered in Walldorf, Germany, SAP is the world's leading provider of cross-enterprise software, and the world's third largest provider of software. SAP today employs more than 28,900 people in more than 50 countries. It is made up of a set of modules adapted to the needs of different industries (aeronautics, chemistry, electronics, mechanics) or services (insurance, banking, health, etc.).

The $\mathrm{R} / 3$ software package is structured in three main areas:

- Finance: accounting and financial applications

- Logistics: flow management

- Human resources: everything related to personnel management 
However, the implementation of an ERP like SAP have impact on the company, both at strategic and structural level.

\section{ERP Implementation}

An ERP is a real project which is characterized by a total integration of a software tool within an organization. Its implementation in the company leads to significant changes in the work habits of a large part of the employees.

In this part, we will present the phases of ERP implementation projects as well, the model of Markus and Tanis (1999).

Before setting up an ERP, each department had its own information system. To make the link between these different systems, the following situations occurred:

- Double or even triple entry of the same information in separate information systems.

- At best, the company had IT interfaces developed between their different IS.

The harmful consequences could be reflected in the event of double entry: there was a high number of errors and inconsistencies between the different IS. In the event of an interface between different IS, the update was not done in real time. Data loss sometimes occurred due to a computer problem during data transfer. Human errors also occurred regularly (transfer of the wrong file, duplicates due to two unsuccessful successive transfers, etc.). In some large companies, management controllers were specifically hired to analyze and correct inconsistencies between these information systems.

For example, at a large computer hardware manufacturer, a stock analyst had to reconcile the discrepancies between the system recording physical entries and exits of stock on one side and the corresponding accounting entries on the other.

Differences of several tens of thousands of euros were regularly noted and had to be explained and then corrected. This mode of operations was very costly for the company and has become unacceptable. To end this situation, the companies decided to implement an ERP.

\subsection{The Phases of the ERP Implementation Project}

Akkermans and Helden (2001) focused their attention on the ERP implementation approach while trying to show that the incremental, evolutionary approach, based on continuous improvement constitutes a key factor for the success of the implementation of an ERP project.

Olson and Davis (1985) defined 'implementation as preparing a business to receive an information system to use it effectively'. The outcome of the implementation extends to a change in tasks, structures and staff.

Yves De Rongé (2000) offers a 5-step method aimed at better planning.

(1) The choice of an ERP solution: The firm specifies the needs to be met by its information systems and analyzes the solutions offered on the market.

(2) Analysis of management processes: this phase involves a double analysis:

- Understand how organizational processes work and identify problems in lost time

- Set up information systems.

(3) Reengineering: the choices made during this phase have repercussions on the organization and its staff.

(4) The particularization of the ERP: the particularization is dictated by strategic and structural choices.

(5) Implementation: adaptation to the new system is through the training of staff and fluid communication between the different players called to learn the logic of integration.

\section{The Foundations of Management Control}

The information's system is the pivotal organ of the strategy and the monitoring of its effectiveness and it is in charge of the efficient modeling of information management. It plays an important key role in steering increasingly complex organizations.

In this part, we will spread the definitions of management control and the role of management controller

\subsection{Management Control}

The definition of management control has been the subject of several books which have contributed significantly to the development of the role and scope of the discipline. 
We will explain the different definitions of management control as well as the role of the management controller and the perception of management control.

\subsection{Definitions of Management Control}

According to the definition of Anthony (1988) "The relationship between information processing and the function of management control generally resembles that of an economic network with their users."

The company's results (production, commercial activity, stocks, return on investment, etc.) appeared through the dashboard tool, which is produced from programs for collecting and processing accounting and financial information developed with engineers. This definition shows the importance of IS for management control.

Management control can be defined as the decision support process. It must inform decisions and make provisional budgets in order to develop the tools necessary for monitoring results (dashboards, indicators) and to highlight discrepancies and explain the causes.

According to Grenier (1990) "management control seeks to design and implement information tools intended to enable managers to act while achieving overall economic coherence between objectives, means and achievements. It must be considered as an information system useful for running the business, since it controls the efficiency and effectiveness of the actions and means to achieve the objectives."

For our work, we retain the last definition because it emphasizes the links between information system and management control.

\subsection{The Role of the Management Controller}

The management controllers of large companies are increasingly faced with information systems articulated around integrated management software. Decision systems can help them in their work. Faced with the standardization of information sources and this "software vision" which is imposed on them, management controllers must compose and equip themselves with tools capable of integrating into sometimes complex structures and environments.

The appearance of new technologies changes the organization of the management control function. In fact, the management controller is confronted with two logics: the financial concern emanating from the hierarchy and the message of performance to the concrete coming from the field. Its role is to help managers in decision-making and to influence the behavior of cost objectives (level of production to be achieved, financial, human and technical resources to be implemented).

Therefore, the management controller must be attentive to the internal and external environment of the company to identify primitive developments and possible changes.

It must also collect the information, memorize it while waiting for its use, process the data and finally communicate this information.

A management controller must know how to collect information, modulate it, make it readable and understandable, but not only. One of the essential contributions of this profession for managers is to constitute a decision aid.

\subsection{The Perception of Management Control}

According to H. Bouquin (2008) "The perception of management control is an essential factor for the success of the management controller". Indeed, this author leads the operational staff to accept it and take his opinions into account".

As a result, the management controller is perceived as an auditor or an inspector when he has neither the vocation nor the authority to judge and sanction. In addition, if he contributes to the management of the company, he is not responsible for it.

\section{The Empirical Validation}

This part will be devoted to empirically testing the model developed. It will present the development of the research model necessary for the empirical verification of the pre-established model and will present the research methodology as well as the results of the descriptive analyzes, the validation of the measurements and the analysis and interpretation of the results

\subsection{The Model and Research Hypotheses}

An ERP system is effective on an individual level and therefore the expected success is achieved when its users are satisfied with it. This level of satisfaction is determined by a good quality of the information provided, a 
good quality of the system installed in the company, a high usefulness perceived by its users and finally a good management of the communication necessary for its implementation.

Thus, the various components of the proposed model for measuring the satisfaction of users of an ERP system, detailed below, can be schematized according to the figure below.

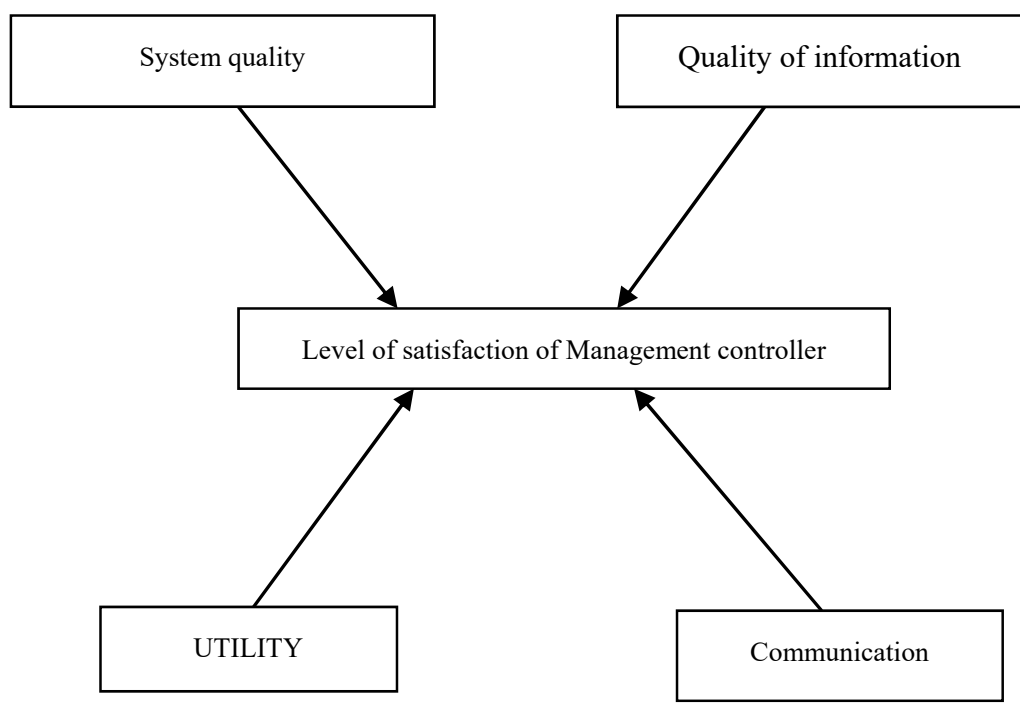

Figure 1. Conceptual model of satisfaction measurement

The research model we propose includes the following variables (quality of the system, quality of information, utility, communication and level of satisfaction of the management controller).

We seek to measure how to explain the satisfaction of management controllers of an ERP system by the key success factors (KSF) that we gathered during our research. Hence the satisfaction of controllers or users is one of the main objectives that an organization tries to achieve. We are trying to confirm or deny the existence of a relationship between these variables.

Confirmation or denial of the existence of this correlation would make it easier to identify the minimum prerequisites for the impact of an ERP project on management control.

The ERP systems implementation assessment will be measured by the satisfaction of the management controllers, which will be considered as the variable to be explained in our model. While the explanatory variables will be the quality of the information provided, the quality of the proposed system, the utility and the communication. Also, we will make sure to determine what dimensions can have an effect on the satisfaction of management controllers, hence our work, in this part, will consist in checking the following hypotheses:

Hypothesis 1: The better the quality of the information provided by the ERP system, the higher the level of satisfaction of the management controller

Hypothesis 2: The better the quality of the ERP system, the higher the level of satisfaction of the management controller

Hypothesis 3: The better the utility perceived by the users, the higher level of satisfaction of the management controller

Hypothesis 4: The better the communication between users, the higher the controllers' satisfaction is increased

After having developed the research model as well as the different scales of measurement of the research variables, it is then necessary to move on to data collection and this by developing a survey which constitutes the material support for the collection of data during the investigation.

In fact, this mode of data collection is the most developed in quantitative research, it makes it possible to directly question individuals by defining, beforehand, by a qualitative approach, the response methods through so-called "closed" questions, and this by choosing between proposals already formulated by the investigator. In fact, this method facilitates the use and coding for the statistical exploitation of the answers.

In our survey, we tried to group the questions by theme in the most coherent way possible, according to the information that we set out to collect and the hypotheses that we proposed to test. 
However, concerning the administration of the survey which constitutes the stage which follows the development of the questionnaire, it is important to note that there are several types of administration of the survey of which one can quote the postal way, the face to face, by telephone or by computer, namely by E-mail, however none of these methods is ideal, and therefore one should look for the advantages and disadvantages of each and this according to the situations that arise.

\section{The Results}

We will present the results in this paragraph the distribution of the 30 companies surveyed according to the different criteria. We are going to perform frequency distributions for all variables.

We treated the results of the simple sorting carried out on SPSS version 20. This sort related to the general information relating to the company visited and to the interviewees appearing in the first part of the questionnaire.

This general information relates to the age, sex of the respondents, their level of education, their specialty, their job and their seniority in the company. Then information's about the company, in particular concerning the type and the sector of activity to which it belongs.

Indeed, concerning the location and therefore the cities to which the sample belongs, it is noted that the population is localized for the most part in the area of Tunis center and the others are located in southern and west area in Tunisia.

The following tables summarize the information relating to these variables in terms of absolute frequency and percentage.

Table 1. Age of respondents

\begin{tabular}{llllll}
\hline & & Frequency & $\%$ & Valid \% & \% Cumulative \\
\hline Valid & 20-30 year & 5 & 11,9 & 16,7 & 16,7 \\
& 30-40 year & 8 & 19 & 26,7 & 43,3 \\
& 40-50 year & 16 & 38,1 & 53,3 & 96,7 \\
& More than 50 year & 1 & 2,4 & 3,3 & 100 \\
& Total & 30 & 71,4 & 100 & \\
Missed & Missed system & 12 & 28,6 & & \\
Total & & 42 & 100 & & \\
\hline
\end{tabular}

The population questioned is rather adult, $53.3 \%$ of the population is aged between 40 and 50 (Table 1). This is explained by the fact that ERP projects are directed in most cases by adults. They are often better qualified either because they are specialists or experienced by "learning by experience" when they are not trained in the specialty in question.

Table 2. Educational level

\begin{tabular}{llllll}
\hline Table 2 & Level of education & Frequency & $\%$ & Valid \% & \% Cumulative \\
\hline Valid & University & 30 & 71,4 & 100 & 100 \\
Missed & Missed system & 12 & 28,6 & & \\
Total & & 42 & 100 & & \\
\hline
\end{tabular}

We find that the education level of respondents is relatively high $71.4 \%$ according to (Table 2). The majority have a higher level. 
Table 3. Function of respondents

\begin{tabular}{|c|c|c|c|c|c|}
\hline & & Frequency & $\%$ & Valid \% & $\%$ Cumulative \\
\hline \multirow[t]{16}{*}{ Valid } & Commercial director & 2 & 2,4 & 3,4 & 3,4 \\
\hline & Logistcics coordinator & 1 & 2,4 & 3,4 & 6,9 \\
\hline & Accounting manager & 2 & 4,8 & 6,9 & 13,8 \\
\hline & Human Resources & 5 & 2,4 & 3,4 & 17,2 \\
\hline & Manager of ERP trainer & 2 & 9,5 & 13,8 & 31 \\
\hline & Sales manager & 2 & 4,8 & 6,9 & 37,9 \\
\hline & Acconting & 3 & 4,8 & 6,9 & 44,8 \\
\hline & Finance manager & 2 & 7,1 & 10,3 & 55,2 \\
\hline & Manager controller & 4 & 4,8 & 6,9 & 62,1 \\
\hline & Manager of ERP & 1 & 7,1 & 10,3 & 72,4 \\
\hline & Expenditure manager & 1 & 2,4 & 3,4 & 75,9 \\
\hline & Consultant & 1 & 2,4 & 3,4 & 79,3 \\
\hline & Managing director & 1 & 2,4 & 3,4 & 82,8 \\
\hline & Science computer & 1 & 2,4 & 3,4 & 86,2 \\
\hline & Commercial & 1 & 2,4 & 3,4 & 89,7 \\
\hline & Total & 29 & 69 & 100 & 93,1 \\
\hline Missed & System missed & 13 & 31 & & 96,6 \\
\hline Total & & 42 & 100 & & 100 \\
\hline
\end{tabular}

Table 4. Seniority

\begin{tabular}{llllll}
\hline & & Frequency & $\%$ & Valid \% & \% Cumulative \\
\hline Valid & Less of 2 years & 1 & 2,4 & 3,3 & 3,3 \\
& 2-5 year & 7 & 16,7 & 23,3 & 26,7 \\
& 5-10 year & 6 & 14,3 & 20 & 46,7 \\
& 10-15 year & 15 & 35,7 & 50 & 96,7 \\
& More than 15 year & 1 & 2,4 & 3,3 & 100 \\
& Total & 30 & 71,4 & 100 & \\
Missed & Missed system & 12 & 28,6 & & \\
Total & & 42 & 100 & & \\
\hline
\end{tabular}

The majority of respondents $50 \%$ have experience of more than 10 years. Experience is important especially in this area.

We now review the information relating to the companies subject to the investigation.

Table 5. The nature of ERP

\begin{tabular}{llllll}
\hline & & Frequency & $\%$ & Valid \% & \% Cumulative \\
\hline Valid & SAP & 9 & 21,4 & 30 & 30 \\
& ADONIX & 3 & 7,1 & 10 & 40 \\
& SAGE & 6 & 14,3 & 20 & 60 \\
& PEOPLE SOFT & 2 & 4,8 & 6,7 & 66,7 \\
& ORACLE & 3 & 7,1 & 10 & 76,7 \\
& CIEL & 6 & 14,3 & 20 & 96,7 \\
& Other ERP & 1 & 2,4 & 3,3 & 100 \\
& Total & 30 & 71,4 & 100 & \\
Missed & Missed system & 12 & 28,6 & & \\
\hline
\end{tabular}

Regarding the type of ERP implemented in Tunisian companies, we note that most of them have used SAP with (30\%) and the rest with SAGE and CIEL (20\%). However, it should be noted that there are other editors in 
Tunisia like Oracle, JD Edwards and ADONIX but which are not used much for reasons of lack of references in our country and it is especially due to their rather high costs.

The importance of the "Quality of information"

The results of the statistical analyzes concerning the explanatory variable "Quality of the information", are summarized in the Table 6 below:

\begin{tabular}{lll}
\hline & satisfaction of & \\
& Management control & \\
\hline Dimension & Pearson Correlation & Signification (sig) \\
Quality of information & 0.728 & $0.000^{* *}$ \\
\hline
\end{tabular}

(**) Seuil signification $1 \%$.

From these results, we note that there is a significant and positive relationship between the quality of the information and the satisfaction of the controllers because these two variables are positively correlated. The first hypothesis H1: "The better the quality of the information provided by the ERP system, the higher the controllers' satisfaction" is generally verified. To refine the analyzes, we treat the relationship between the satisfaction of management controllers and the factors of the quality of information.

According to the results of the purification, we grouped the items of the satisfaction of the management controllers and we identified it as " the optimization of the system ", thus, we factorized the variable quality of information in two factors, namely the benefits of quality of information and clarity of information. The results of the statistical analyzes concerning the two factors of the explanatory variable "quality of the information", are summarized in Table 7 below:

\begin{tabular}{lll}
\hline & \multicolumn{2}{c}{ The optimisation of system } \\
\cline { 2 - 3 } Dimension & Pearson Correlation & Signification (sig) \\
\hline F1 (the advantages of information quality) & 0,439 & $0.000^{* *}$ \\
F2 (the clarification of information) & 0,318 & $0.000^{* *}$ \\
\hline
\end{tabular}

(**) Seuil signification $1 \%$.

Hypothesis 1 is confirmed, there is a positive and significant relationship between the benefits of information quality and system optimization, information clarity and system optimization.

These results therefore clearly confirm the fact that the information provided by the ERP system or software is presented in a format suitable for the use of each of the various services and for their smooth operation. Likewise, this information is clear, accurate, on time and updated for better decision-making.

Likewise, ERP systems offer uniqueness of information since the input of this information is localized in a single repository, thus avoiding redundancies and inconsistencies. Indeed, "The single repository, which is technically produced by the presence of a relational database, is the foundation of all the computer programs present in ERP systems and promotes information consistency. Information capture is located in the organization in a single place which avoids inconsistencies and redundancies".

So, what we can say is that the " good quality of information " is only made possible thanks to the information integration offered by ERP systems, since the latter promotes exchanges of information's between the different departments, makes it possible to give greater consistency to the organization, which will therefore make it possible to coordinate certain processes in the company. This will thus give the controllers satisfaction since their objectives are achieved following the obtaining of information fully adapted to their needs.

The importance of "System quality":

The results of the statistical analyzes concerning the variable "quality of the system" are summarized in the table 8 below:

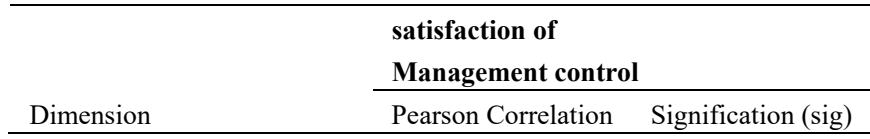




\begin{tabular}{lll}
\hline Quality of system & 0.496 & $0.002^{*}$ \\
\hline (*) Seuil signification 5\% & &
\end{tabular}

From this table, we note, overall, that there is a significant and positive relationship between the quality of the system and the satisfaction of users because these two variables are positively correlated, hence the hypothesis $\mathrm{H} 2$ according to which "The better the quality of the ERP system, the better the satisfaction of the controllers" is verified.

What we observe in relation to this hypothesis is that the influence of the quality of the system is less important than that of the information provided, and this on user satisfaction. However, this does not prevent from concluding that the effect of the quality of the ERP system on satisfaction is positively significant but in a fairly average way since the increase of one unit in the quality of the system only leads to the increase of 0.496 units of user satisfaction.

The importance of "Utility":

The results of the statistical analyzes concerning the explanatory variable "Utility" are summarized in Table 9 below:

\begin{tabular}{ccc}
\hline & \multicolumn{2}{c}{ satisfaction of } \\
& \multicolumn{2}{c}{ Management control } \\
\hline Dimension & Pearson Correlation & Signification (sig) \\
Utility & 0.712 & $0.000^{* *}$ \\
\hline
\end{tabular}

(*) Seuil signification $5 \%$.

From this table, we notice that there is a significant and positive relationship between Utility and user satisfaction, hence the overall hypothesis $\mathrm{H} 3$ according to which "The better the utility perceived by users, the better their satisfaction is high" is confirmed. This dimension affects satisfaction more importantly than the quality of the system and slightly less important than the information provided.

The importance of "communication":

The results of the statistical analyzes concerning the explanatory variable "Communication" are summarized in Table 10 below:

\begin{tabular}{lcc}
\hline & \multicolumn{2}{c}{ satisfaction of } \\
& \multicolumn{2}{c}{ Management control } \\
\hline Dimension & Pearson Correlation & Signification (sig) \\
The communication & 0.412 & $0.001^{*}$ \\
\hline
\end{tabular}

(*) Seuil signification 5\%.

According to this table, we notice that there is a significant and positive relationship between communication and user satisfaction, hence the hypothesis $\mathrm{H} 4$ according to which "The better the communication perceived by users, the more their satisfaction is high" is confirmed. This dimension affects satisfaction more significantly than communication and slightly less than information provided. Therefore, this result is normally in line with previous work on the importance of communication in information technology implementation projects.

\section{Conclusions}

In conclusion, ERP radically changed financial accounting practices, by inducing formalization of operations, automation and securing of the recording of operations. They have made it possible to put the event-based approach to accounting into practice (Tondeur \& La Villarmois, 2003).

Data collection represents the main contribution of ERP to management control. In fact, they have led to an undeniable step towards the harmonization and refinement of budget information.

The establishment of an ERP is an organizational project. It establishes has led to the survey of skills and trades as well as a redefinition of power plays and an evolution of the culture of the company and its value system. Hence, they give management control the means of its development: the use of the client / server database, the creation of reports and dashboards adapted to the needs of the user. The role of the management controllers, then, is to provide the indicators conform to the needs of the users.

But studies did on the impact of ERP on the management control function reveal that the instrumentation of technology is rarely faithful to such model. This observation proves the ambiguous nature of the influence of 
ERP on the management control function.

The technical system therefore makes operational and management acts more transparent. Thanks to the standardization of data, they facilitate the consolidation and feedback of information, as well as the role of management controllers and the transfer of accounting knowledge to field managers, which has significantly improved performance through better quality of information, real-time management, easy error identification ...

Like every study, there's some disadvantages on the uses of the enterprise resources planning and poor development planning for conversions and interfaces. In fact, this paper generates some lack of ERP technical expertise.

For the future study, I will Looking at a relationship aspect between information's system and communication determining their potential impact on the quality and the utility of the management user satisfactions'. Indeed, identifying the management of the corporate on 214 cases of industrial corporates.

\section{References}

Attaran, M. (2003). Information technology and business-process redesign. Business Process Management Journal, 9(4), 440-458. https://doi.org/10.1108/14637150310484508

Azan, W., \& Beldi, A. (2007). « Human agency », Erp et Crm: vers des approches centrées sur les utilisateurs? XVIème Conférence Internationale de Management Stratégique.

Baglin, G. (2005). Management industriel et logistique: conception et pilotage de la supply chain. Paris: Economica.

Beldi, A., \& Azan, W. (2013). The contribution of social theories to information system research. International Journal of Auditing Technology, 1(2), 131. https://doi.org/10.1504/IJAUDIT.2013.057334

Berghout, E. (2012). Leading issues in Ict evaluation research. Reading: Academic Publishing International.

Bessire, D., \& Gensse, P. (2009). La revue des thèses. Comptabilité - Contrôle - Audit, 15(2), 199. https://doi.org/10.3917/cca.152.0199

Bouquin, H., \& Kuszla, C. (2014). Le contrôle de gestion : contrôle de gestion, contrôle dentreprise et gouvernance. Paris : Presses universitaires de France.

Bouquin, H., \& Nikitin, M. (2003). Les innovations managériales. Comptabilité - Contrôle - Audit, 9(3), 3. https://doi.org/10.3917/cca.093.0003

Bruns, W. J., \& Waterhouse, J. H. (1975). Budgetary Control and Organization Structure. Journal of Accounting Research, 13(2), 177. https://doi.org/10.2307/2490360

Candra, S. (2011). The Road of ERP Success: A Framework Model for Successful ERP Implementation. Binus Business Review, 2(2), 1118. https://doi.org/10.21512/bbr.v2i2.1254

Cardinal, L. B., Kreutzer, M., \& Miller, C. C. (2019). Organizational Control. Management. https://doi.org/10.1093/obo/9780199846740-0176

Chaabouni, S., Frikha, M., \& Meincke, M. (n.d.). Traffic Models for Inter-Vehicle Communications. 2006 2nd International Conference on Information \& Communication Technologies. https://doi.org/10.1109/ICTTA.2006.1684470

Corps of Engineers Washington Dc. (1990). Management Information Control: Management Information Control System. https://doi.org/10.21236/ADA404680

Dantes, G., \& Hasibuan, Z. (2010). The Impact of Enterprise Resource Planning (ERP) System Implementation on Organization: Case Study ERP Implementation in Indonesia. IBIMA Business Review Journal, 1-10. https://doi.org/10.5171/2011.210664

Editorial Board. (2019). Information \& Management, 56(5), ii. https://doi.org/10.1016/S0378-7206(19)30491-4

Ekayanti, S. R., \& Irwansyah. (2018). UTAUT in Communication Technology of Learning Management System. 2018 International Conference on Advanced Computer Science and Information Systems (ICACSIS). https://doi.org/10.1109/ICACSIS.2018.8618172

Ekayanti, S. R., \& Irwansyah. (2018). UTAUT in Communication Technology of Learning Management System. 2018 International Conference on Advanced Computer Science and Information Systems (ICACSIS). https://doi.org/10.1109/ICACSIS.2018.8618172

Emmanuel, C., Otley, D., \& Merchant, K. (1990). Management control case studies. Accounting for 
Management Control, 387-489. https://doi.org/10.1007/978-1-4899-6952-1_14

Fathi, F., \& Pérotin, V. (2019). France. Paying for Performance, 90-114. https://doi.org/10.4324/9781315701875-4

Grabis, J. (2019). Optimization of Gaps Resolution Strategy in Implementation of ERP Systems. Proceedings of the 21st International Conference on Enterprise Information Systems. https://doi.org/10.5220/0007710000840092

Gut, A., Hoka, I., Miclea, L., Florescu, G., \& Florescu, V. (2008). Globalization solution for a web based community. 2008 IEEE International Conference on Automation, Quality and Testing, Robotics. https://doi.org/10.1109/AQTR.2008.4588949

https://doi.org/10.23883/IJRTER.2017.3291.XUS6S

IEEE Communications Society Information. (2004). IEEE Transactions on Communications, 52(3), c3-c3. https://doi.org/10.1109/TCOMM.2004.826852

Jurnak, F. (1994). The ABC of EF-G. Structure, 2(9), 785-788. https://doi.org/10.1016/S0969-2126(94)00078-6

Khedhaouria, A., \& Beldi, A. (2014). Mobile Internet Services Measure. PsycTESTS Dataset. https://doi.org/10.1037/t39059-000

Langfield-Smith, K. (2006). Understanding management control systems and strategy. Contemporary Issues in Management Accounting, 243-265. https://doi.org/10.1093/acprof:oso/9780199283361.003.0011

Langfield-Smith, K. (2006). Understanding management control systems and strategy. Contemporary Issues in Management Accounting, 243-265. https://doi.org/10.1093/acprof:oso/9780199283361.003.0011

Lebraty, J., \& Reix, R. (1981). La flexibilité dans l'entreprise. Revue Économique, 32(4), 811. https://doi.org/10.2307/3501482

Lu, Y., Wang, J., \& Wu, D. (2018). Design of Project Teaching System for Information Management and Information System under the Perspective of OBE. Proceedings of the 8th International Conference on Social Network, Communication and Education (SNCE 2018). https://doi.org/10.2991/snce-18.2018.50

Mamoghli, S., \& Cassivi, L. (2019). Agile ERP Implementation: The Case of a SME. Proceedings of the 21st International Conference on Enterprise Information Systems. https://doi.org/10.5220/0007700501880196

Management Control and the Automated Budget. (1981). The Management of Information Systems, 207-260. https://doi.org/10.7312/krae93774-008

Markus, M. L., Axline, S., Petrie, D., \& Tanis, C. (2003). Learning from Adopters Experiences with ERP: Problems Encountered and Success Achieved. Second-Wave Enterprise Resource Planning Systems, 23-55. https://doi.org/10.1017/CBO9780511815072.002

Rapport sur la Gouvernance en Afrique V - 2018. (2019). https://doi.org/10.18356/f2ca79b9-fr

Sbarba, A. D., \& Marelli, A. (2018). Family-controlled businesses and management control: the framing of "shareholder-oriented" practices. Journal of Management Control, 28(4), 417-456. https://doi.org/10.1007/s00187-018-0255-3

Sekimoto, M. (2018). Development of interface of hydroponic culture management system using AR. International Journal of Digital Information and Wireless Communications, 8(4), 304-309. https://doi.org/10.17781/P002538

Spencer, M. L. G. (2018). Crisis-Management, Censorship, Control. Stalinism and the Soviet-Finnish War, 1939(40), 67-103. https://doi.org/10.1007/978-3-319-94646-7_3

Study on Critical Factors affecting on ERP implementation process. (2017). International Journal of Recent Trends in Engineering and Research, 3(6), 177-181.

The Functions of Management. (2018). Imaginative Management Control, 18-33. https://doi.org/10.4324/9781351260640-2

\section{Copyrights}

Copyright for this article is retained by the author(s), with first publication rights granted to the journal.

This is an open-access article distributed under the terms and conditions of the Creative Commons Attribution license (http://creativecommons.org/licenses/by/4.0/). 